\title{
Oral Administration of Oyster Peptide Prevents Bone Loss in Ovariectomized Mice
}

\author{
Hui Chen ${ }^{1,2}$, Pujie Shi ${ }^{3}$, Zhe Xu1, Fengjiao Fan ${ }^{4, *}$, Zhenyu Wang ${ }^{1}$, Ming $\mathrm{Du}^{1, *}$ \\ ${ }^{1}$ School of Food Science and Technology, National Engineering Research Center of Seafood, Dalian Polytechnic University, Dalian, Liaoning 116034, China \\ ${ }^{2}$ College of Food Science and Technology, Zhejiang University of Technology, Hangzhou, Zhejiang 310014, China \\ ${ }^{3}$ Department of Chemistry and Chemical Engineering, Harbin Institute of Technology, Harbin, Heilongjiang 150090, China \\ ${ }^{4}$ College of Food Science and Engineering, Nanjing University of Finance and Economics, Nanjing, Jiangsu 210046, China
}

\section{ARTICLE INFO}

\section{Article History}

Received 15 July 2020

Accepted 11 August 2020

\section{Keywords}

Osteoporosis

oral administration

bone mineral density

MAPK

ERK

\section{ABSTRACT}

Osteoporosis is a disordered metabolic disease occurred congenitally or secondary. Although peptide agents have been approved to prevent osteoporosis administrated through subcutaneous injection, rare reports focused on peptide oral administration for preventive purpose. An eight peptide, P-CG-01 (YRGDVVPK) derived from oyster protein hydrolysates in gastrointestinal tract can promote the proliferation of osteoblast in vitro. In this study, ovariectomized mouse model was used to investigate the osteogenesis activity of P-CG-01. Bone mineral density value was recovered to the level of Sham by treatment of peptide [30 mg/kg body weight (BW)] in the ovariectomized mice. Peptide was detected at an average concentration of $803.16 \mathrm{ng} / \mathrm{mL}$ in serum from those mice after gavage. The peptide was labelled with fluorescein isothiocyanate and detected in the cytoplasm of osteoblast by confocal microscopes. ERK2 and BMP-2 expression was increased 1.5- and 3.8-fold, respectively, by the treatment of peptide. Our results suggest that P-CG-01 can inhibit the development of osteoporosis in ovariectomized mice.

\section{GRAPHICAL ABSTRACT}

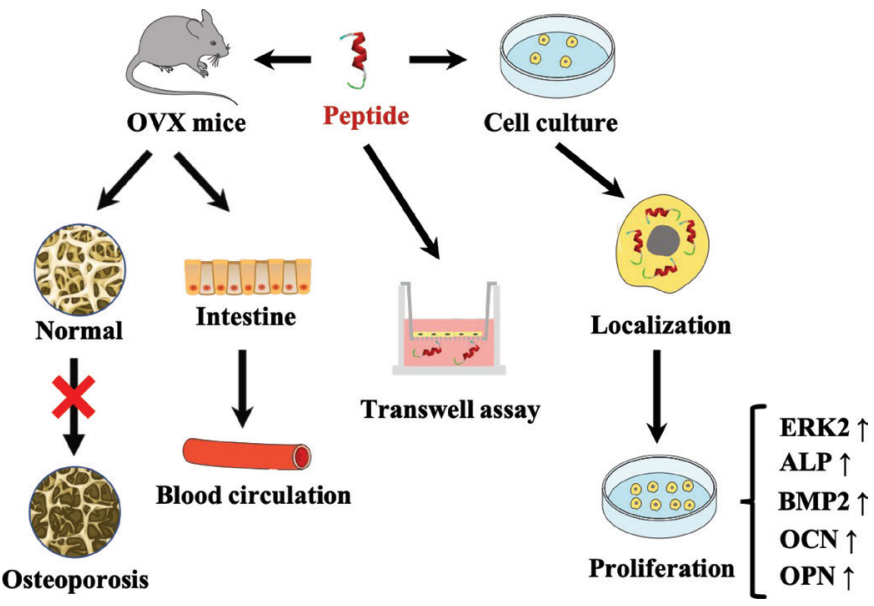

(C) 2020 International Association of Dietetic Nutrition and Safety. Publishing services by Atlantis Press International B.V. This is an open access article distributed under the CC BY-NC 4.0 license (http://creativecommons.org/licenses/by-nc/4.0/).

\section{INTRODUCTION}

Osteoporosis is a bone degenerative disease occurred in the population of postmenopausal women and elderly men. The fundamental cause of osteoporosis is the destruction of dynamic balance of

"Corresponding authors. Email: fanfjklyx@nufe.edu.cn; duming@dlpu.edu.cn Peer review under responsibility of the International Association of Dietetic Nutrition and Safety bone homeostasis, that is, the rate of bone formation of osteoblasts is less than the rate of bone absorption of osteoclasts, leading to the decrease of overall bone mass in the body. Osteoporosis can result in hip fractures, vertebral compression in common, and other bone fractures. According to current statistics, approximate one in every two women and one in every five men suffer from bone fractures [1].

Although the anabolic agent of various protein, such as, Parathyroid Hormone (PTH), PTH-related Protein (PTHrP) [2], 
Bone Morphogenetic Protein-2 (BMP-2), osteoprotegerin and platelet-derived growth factor that increase bone formation, some molecules are not suitable for drug therapy because they are expensive, subjected to enzymatic degradation, have limited supply, and even decrease the Bone Mineral Density (BMD) value on peripheral skeleton at high dose [3]. Thus, novel anabolic agents that can rapidly promote bone formation or treat bone loss are needed. The form of a shorter sequence of peptides represents a series of superiority that binds specifically to their targets in vivo, exerts high efficiency of biological action and has side effects because of moderate non-specificity. The peptide agent application can be used not only in systemic injections, but also as oral pills in clinical setting. Though the bioavailability of injection administration is greater, oral delivery are more convenient and acceptable for patients. The route of oral injection of circulation protein or peptide-based agents has to overcome a range of barriers. The molecules may be proteolytic cleaved in gastrointestinal tract to prevent permanent damage on mucosa of membrane. In addition, entrance into hepatic vein may also hinder their property, including molecular size, polarity, dosage. However, many attempts have been made for development of oral drug of peptide. Salmon calcitonin, human PTH (1-34), and human PTHrP (1-36) have been tested in different stages of clinical testing for treating osteoporosis [4-6].

Recent years, research on food-derived nutraceutical functional proteins suggest that oral use of antiosteoporosis peptides in short length may play a complementary role for therapeutic treatment, which can increase BMD value and prevent bone loss. A 6-month oral administration to subjects who are 44-59 years old, the average BMD was higher compared to the control group especial for women [7]. A nutraceutical product obtained from protein hydrolysates of collagen or gelatin are proposed to be helpful for the maintenance of normal bone and tendon health, and improving brittle nail treatment $[8,9]$. Proteins and their fragment isolated form Mytilus edulis enhance the proliferation of mouse preosteoblast cell by increasing the ALP activity [10]. Those results indicate that peptides originated from natural food could be an anti-osteoporotic agent to maintain bone mass level via oral administration.

Marine protein resources are abundant in shellfish. The discovery of bioactive roles of peptides in aquatic food suggest that the peptides can be developed as potential nutraceutical for disease treatment. In our previous study, one novel oyster-derived P-CG-01 exerts an osteogenic activity of pre-osteoblast (MC3T3-E1) in intro [11]. The peptide was obtained from pacific oyster via the mimic gastrointestinal digestion and the peptide was resistant to gastrointestinal digestion. However, the peptide's anti-osteroporotic effect in vivo is unknown. The current study, ovariectomized mice, an osteoporosis model, were treated with the peptide orally. The bone mass of those mice was evaluated by micro-CT scanning. The absorption of the peptide into circulation and the cellular localization of osteoblast together with the mechanisms of action were investigated.

\section{MATERIALS AND METHODS}

\subsection{Materials and Chemicals}

The authentic standards of all organic reagent used in mass spectrometry analysis were Mass Pure Grade. All the cell lines were purchased from the Cell Bank of Chinese Academy of Sciences, Shanghai, China. Isoflurane (RWD Life Science, Shenzhen, China) was used to euthanize the mice.

\subsection{Cell Culture}

MC3T3-E1 cells were incubated immediately once cell lines were arrived. Medium for cells culture was $\alpha$ Minimum Eagle Medium (MEM, Hyclone, IL, USA) with addition of fetal bovine (10\%, PAN-Biotech, UK). Medium for Caco-2 cell lines was 80\% MEM (Hyclone), 20\% fetal bovine. Cells were firstly cultured in a culture flask (Corning, NY, USA) for three generations at $37^{\circ} \mathrm{C}$ and $5 \%$ high-purity $\mathrm{CO}_{2}[12,13]$. Then they were transferred into 6-well plates (Corning, NY, USA). Medium was replaced every 2 days. P-CG-01 was dissolved in the medium at the concentrations of $2.5,25$, and $100 \mathrm{nM}$. The peptide was added into 6-well plates after the cells were attached about $24 \mathrm{~h}$.

\subsection{Animal and Osteoporotic Mouse Model}

Female C57 mice at 10 weeks old were purchased from Dalian Medical University (L20160258). They were randomly housed six per group in one cage on a cycle of 12-h light/dark cycle. Temperature of housing room was maintained at $22 \pm 2{ }^{\circ} \mathrm{C}$, and relative humidity was constant at $55 \pm 5 \%$. Prior to any intervention and throughout the entire research, mice had free access to water and commercial rodent chow (AIN 93 purified diets). Body weight of mice was measured weekly. Animal care procedures were complied with Principles of Laboratory Animal Care. All protocols complied with the policy statements of the Animal Management Regulations (2017) on the research of experimental animals.

Ovariectomized mice (OVX group, $n=10$ ) and those with fat near ovarian removed (Sham group, $n=10$ ) were allowed to recover for 2 weeks. Ovariectomized mice (OVX + E2 group, $n=10)$ subcutaneously injected with estrogen-2. P-CG-01 (OVX + SP3 group, OVX + SP10 group, OVX + SP30 group, in three concentrations, $3,10,30 \mathrm{mg} / \mathrm{kg} \cdot$ day, respectively, $n=10$ ) was intragastrically administered. Sham and OVX group were allowed the same amount of water. Osteoporosis in OVX mice were examined by micro-CT scan of trabecula comparing to Sham. In this study, potential osteogenesis peptides were used to prevent the loss of estrogen in ovariectomized mice. At the end of the research, mice were younger than the age when the ovary was about to decline. At 3 months, bilateral femur of specimens and blood samples were collected for further investigation.

\subsection{Osteoclast Differentiation from RAW264.7 Cell}

To evaluate the effect of peptide on Receptor Activator of Nuclear Factor Kappa $\beta$ Ligand (RANKL)-induced RAW264.7 cells differenced into osteoclast, RAW264.7 $\left(1 \times 10^{3}\right.$ cells per well $)$ were cultured in DMEM and allowed to attach overnight. Medium then added with peptides $(0,2.5,25,100 \mathrm{nM})$, with and without $100 \mathrm{ng} / \mathrm{mL}$ RANKL, with and without $50 \mathrm{ng} / \mathrm{mL}$ macrophage-colony stimulating factor (M-CSF). Cells were cultured for 4 days with the medium $[14,15]$. 


\subsection{Alkaline Phosphatase Activity in Osteoblast and Mice Blood}

Alkaline Phosphatase (ALP) activity assay used a tube free of heat resource and endotoxin and avoided any stimulation to cell. Mouse serum was obtained after centrifugation at $3000 \mathrm{~g}$ for $20 \mathrm{~min}$. Alkaline phosphatase in mouse serum and Caco- 2 cells were detected by an ALP assay kit $[16,17]$. Protocols of ALP activity were referred to the manufacture manual, which can recognize the wild type and recombinant ALP specificity in mice.

\subsection{Tartrate-resistant Acid Phosphatase Activity in Osteoclast and Mouse Blood}

Tartrate-resistant acid phosphatase (TRAP) activity assay used a tube free of heat resource and endotoxin and avoided any stimulation to cell. Mouse serum was obtained from the method above. TRAP activity in supernatant and in mouse serum was detected by a TRAP assay kit (Beyotime, Shanghai, China) [18,19]. The operation procedure was according to the standard protocol. Samples were added into the 96-well, where TRAP can dephosphorylate the para-nitrophenyl phosphate into para-nitrophenyl under acid condition. Finally, 96 wells were read by a microplate reader (Infinite M200, Tican) under alkaline $\mathrm{pH}$.

\subsection{Cell Cycle by FCM}

Cells were fixed with $70 \%$ ethanol in fixator at $4^{\circ} \mathrm{C}$ for $1 \mathrm{~h}$, and the suspension in PBS was kept for $10 \mathrm{~min}$. After Propidium Iodide [PI, $10 \mathrm{~g} / \mathrm{L}$, Sigma (MO, USA)] staining, a flow cytometry (FACScan, Becton and Dickinson, CA, USA) was used to detect fluorescence of cultured cells. Cell nucleus can transform the beam of $488 \mathrm{~nm}$ argon laser to a range emission from about 560 and $600 \mathrm{~nm}$ (bandwidth $35 \mathrm{~nm}$ ). Red fluorescence of DNA with PI staining was collected, and the data were recorded on a logarithmic scale. The Forward Scatter (FSC) and side scatter of cells were achieved in real-time. All data were analyzed using official FACScan software for research use (Becton and Dickinson) $[20,21]$. Cell fragments were rejected from analysis by appropriate threshold of FSC.

\subsection{Transwell Assay}

Caco-2 cells were cultured at count about $10^{5}$ cells/well in apical compartment of a commercial transwell (Corning, NY, USA). Resistance of cell was monitored by a resistor (MERS00002, MilliporeSigma, USA) in everyday culture to make sure the monolayer of cell lines. Resistance was controlled transepithelial electrical resistance (TEER) value between 300 and $1000 \Omega \cdot \mathrm{cm}^{2}$, until it exceeds the extreme growth [22]. Extremum of Caco-2 ALP was calculated by the ALP activity ratio of AL/BP of each well. Concentration of $500 \mu \mathrm{g} / \mathrm{mL}$ peptides were added into each well in three replicates. Then incubation was kept for 15, 30, 60 and 120 min. Medium of basal compartment was deproteinized using salts in medium via polar phase elution through the SPE C18 column $[23,24]$. Peptide penetrated concentration in basal compartment was detected by UPLC-MS method, which is described below.

\section{9. $\mathrm{P}-\mathrm{CG}-01$ Absorption in vivo}

C57 mice were fasted $18 \mathrm{~h}$ in advance. Animal of peptide-induced absorption in C57 mice in this experiment has been published in previous reports [25]. Random grouping was used and mice (six/ group) received oral administration of peptide (per os $30 \mathrm{mg} / \mathrm{kg}$ BW). Besides, control group was intragastrically administrated with water. Orbital vein method was used to collect blood. And $100 \mu \mathrm{l}$ blood samples were collected at 5, 10, 20, $30 \mathrm{~min}, 1 \mathrm{~h}, 2$, 4, and $12 \mathrm{~h}$ after mice received ether anesthesia. Serum was harvested by centrifugation at $3000 \mathrm{~g}$ for $15 \mathrm{~min}$, then it was stored at $-70^{\circ} \mathrm{C}$ for further analysis. And serum was deproteinized and desalted via polar phase elution through the SPE C18 column [23]. Peptide concentration was detected by UPLC-MS method, which is described below.

\subsection{Quantification of P-CG-01 by HPLC-MS/MS}

Method of P-CG-01 culture on transwell assay and in mouse serum was identified by a HPLC (SHIMADZU, Osaka, Japan) coupling MS [AB SCIEX QTRAP 5500 (AB Sciex, CA, USA)]. Column was with a flow of $0.3 \mathrm{~mL} / \mathrm{min}$. Elution started at $12 \%$ of phase $B$ ( $0.1 \%$ formic acid in acetonitrile) to $30 \%$ phase B in $3 \mathrm{~min} ; 30-95 \%$ phase $\mathrm{B}$ in $1 \mathrm{~min} ; 95-12 \%$ phase $\mathrm{B}$ in $0.2 \mathrm{~min}$, till the end in 5 min. Parameters on MRM of P-CG-01 was adjusted by direct injection into MS. Declustering Potential (DP) and Collision Energy (CE) were tuned for the highest ion intensity, 140 and $44 \mathrm{kV}$, respectively.

\subsection{RT-qPCR}

RNA of cells treated with P-CG-01 was extracted. Total mRNA reverse transcription to cDNA was performed according to the manufacturer's protocol (PrimeScript ${ }^{\text {tw }}$ RT reagent Kit with gDNA Eraser, Takara, Dalian, China). Reaction system volume was set as $20 \mu \mathrm{l}$ in total. Eleven putative reference genes were designed from the US National Center for Biotechnology Information (NCBI) database or reported stable gene expression. Primer sequences (purchased from Sangone Biotech, China) was cross-checked. Quantitative PCR was performed on qTower 2.2 system in an 8 well PCR Strip tubes (AXYGEN, CA, USA). Reaction system was carried out from the kit method of TB Green ${ }^{\text {TM }}$ Premix Ex Taq ${ }^{\text {TM }}$ II (Tli RNaseH Plus, Takara). Briefly, samples were amplificated in $95^{\circ} \mathrm{C}$ for $30 \mathrm{~s}$ with enzyme activation, and then modified 40 cycles in $95^{\circ} \mathrm{C}$ for $5 \mathrm{~s}$, and then annealed $30 \mathrm{~s}$ at $60^{\circ} \mathrm{C}$. Melting curve was analyzed at the end of each run, from $65^{\circ} \mathrm{C}$ to $95^{\circ} \mathrm{C}[26,27]$. Mean value of all samples and positive controls were used for analysis of gene expression change fold, which were conducted in quadruple. Quantization period $(\mathrm{Cq})$ above 35 was excluded. Primer list of extracellular signal-regulated kinase (ERK)1/2, p38, ALP, Runt-related transcription factor 2 (RUNX2), Osteocalcin (OCN), Osteopontin (OPN), BMP-2 gene are designed as below.

\subsection{Confocal Microscopy}

P-CG-01 was labelled by fluorescein isothiocyanate (FITC) at N-terminal, which was identified by MS (LXQ 10310, Thermo Fisher Scientific, MA, USA) with direct injection. And excitation wavelength and emission wavelength were confirmed by a 
fluorophotometer (F-2700, Hitachi, Japan). MC3T3-E1 cell line was cultured in a $35 \mathrm{~mm}$ confocal well overnight for 80,000 per well. Next day, cell nucleus was stained with 4',6-Diamidino-2Phenylindole, Dihydrochloride (DAPI, $10 \mu \mathrm{g} / \mathrm{mL}$ in cell culture medium) for $30 \mathrm{~min}$. Then confocal well was washed by PBS three times, $5 \mathrm{~min} /$ time. A confocal chamber (GSI-D35, Corning, NY, USA) on an automatic stage was used to keep the confocal well at the circumstances of $37^{\circ} \mathrm{C}, 5 \% \mathrm{CO}_{2}$. Cells were observed under the confocal (TSC SP8, Leica, Germany) after the P-CG-01-FITC was added into the well for 5, 10, 20, 30, and $60 \mathrm{~min}$. Excitation wavelength of DAPI was set to $405 \mathrm{~nm}$, and emission wavelength was from 434 to $464 \mathrm{~nm}$. Excitation wavelength of P-CG-01-FITC was set to $490 \mathrm{~nm}$, and emission wavelength was from 515 to $535 \mathrm{~nm}$. Magnification of the objective and eyepiece lenses were $20 \times$ and $10 \times$, respectively. A more $8 \times$ magnification was used to observe the single cell from the local-field of confocal.

\subsection{Western Blotting}

P38, ERK, OSX, RUNX2, BMP-2 proteins are the crucial biomarker of MC3T3-E1 cell during the proliferation time. And all above antibodies were purchased from Proteintech (IL, USA). Proteins were extracted from MC3T3-E1 cell after treatment with P-CG-01 for 72 h. Cell lysis buffer for Western blotting (Beyotime, Shanghai, China) containing $1 \mathrm{nM}$ PMSF was used to lyse cells to obtain proteins. And protein concentration was measured by the Bradford protein assay (Beyotime) to calibration of equivalent quality for sample loading. Proteins were loaded on a SDS-PAGE to be separated by electrophoresis system (Bio-Rad, CA, USA). Proteins on the PAGE were transferred to the polyvinylidene difluoride (PVDF) film. After blocking for $1 \mathrm{~h}$, PVDF membrane was incubate with primary antibody $(1: 1000)$ for $2 \mathrm{~h}$ at room temperature. Then it was washed by TBST buffer for 3 times. Same procedure was for second antibody (1:2000) incubation. Electrochemiluminescence was used for chromogenic reaction for 30 min (BeyoECL Plus, Beyotime) [28,29]. Finally, film was scanned or photographed, and molecular weight and net optical density of target band were analyzed by the gel image processing system (MF-ChemiBIS 2.0, DNR, Jerusalem, Israel).

\subsection{Micro-CT Analysis}

Prior to micro-CT analysis, mice were anesthetized with the mixture of oxygen and isoflurane, at a flow rate of $0.2 \mathrm{~mL} / \mathrm{min}$. Trabecular spongiosa at the left femur from each mouse was scanned ex vivo using a micro-CT system (SKYSCAN1272, Bruker, Germany). Operational parameters were as below: X-ray voltage, $50 \mathrm{kV}$; Filter, $0.5 \mathrm{~mm}$ aluminium. Briefly, the Region of Interest (ROI) was selected on the cross-sectional slice of reconstruction dataset from the scan of instrument. Trabecular region was defined as a reference slice of growth plate from the position of four islands, which was sketched by chondrocyte seams. The ROI was extended to $1.72 \mathrm{~mm}$ at the beginning of $0.22 \mathrm{~mm}$ from the growth plate along the axis of distal femur. All the trabecular bone in ROI was converted into 3D model $($ sigma $=1.2$, supports $=2$ and threshold $=180)$ to calculate the bone formation parameters including BMD, Bone Volume/Tissue Volume (BV/TV), trabecular thickness, trabecular numbers, trabecular separation, trabecular pattern factor [30]. BMD value was calibrated by phantoms with standard density of CaHA $\left(0.25\right.$ and $\left.0.75 \mathrm{~g} / \mathrm{cm}^{3}\right)$.

\subsection{Bone Tissue Slice}

Mouse tibia was picked out, and muscle tissue was removed as much as possible. Tibia was soaked in hydrochloric acid solution for 2 days to decalcify calcium in matrix, which reduced its hardness for easy slicing. Before specimen was made, bone was fixed in paraformaldehyde (4\%) and embedded by a paraffin embedding station (EG1150H, Leica) [31,32]. Longitudinal section of each tibia was cut into 20 slices with a paraffin slicing machine (RM2245, Leica). Slice thickness was adjusted to 5-6 $\mu \mathrm{m}$. Hematoxylin-Eosin staining was used to dye mouse specimen after dewaxing. From the tibial femoral as the starting point to the tibial end, $5 \mathrm{~mm}$ was selected as the bone trabecular region. Finally, specimens were observed by light microscope (TI-DH, Nikon, Tokyo, Japan).

\subsection{Statistical Analysis}

Data were analyzed statistically and diagramed using Origin 8.0 (OriginLab, USA). Statistical significance of differences between the group of Sham, OVX, OVX + OP, and OVX + SP were determined by one-way ANOVA with evaluation by Dunnett method. The data were at least three times reduplicates for each sample and six mice per group in animal experiment, which were presented as means \pm standard error $(\mathrm{M} \pm \mathrm{SE})$.

\section{RESULTS AND DISCUSSION}

\subsection{Osteoporosis Protecting Effect of $\mathrm{P}-\mathrm{CG}-01$ in vivo}

The ovariectomized mice were given peptides orally as soon as the health of mice recovered and when the mice were not have the sign of and far from the osteopenia or osteoporosis. All those mice were fed for 2 months, until they were scanned by micro-CT in vivo. During the whole experiment, no toxic effects was found by intragastric administration. Skeletal microstructure of mice femora was evaluated by micro-CT scanning at trabecular region. No apparent differences was found between Sham and experimental groups in the selected region of interest of trabecula. The static bone histomorphometric analysis of trabecula turn-over of bone mass induced by ovariectomy in female mice was performed. Representative trabecular 3D structures were reconstructed to compare the size of the strands in each group, as seen in Figure 1, the trabecular volume of OVX + 30SP group was recovered to the level of OVX + E2 group. The bone tissue slices also can indicate the trabecular thickness near the cortical bone in OVX + 30SP group was greater than OVX, even though the trabecular number was not recovered to the level of Sham, shown in Figure 2.

Bone mineral density is an important index for the evaluation of osteoporosis, and its significant changes can be used to analyze bone health. It can be seen from the results that BMD in OVX group decreased significantly, and the BMD decreased in the model mice was alleviated by the intervention of peptides. Although the index of TV, BV and TV/BV was lower than that of the positive control group treated with estrogen-2, compared with the non-treated control group, the quantity of trabecular bone in all peptide treatment groups recovered in some degrees, 

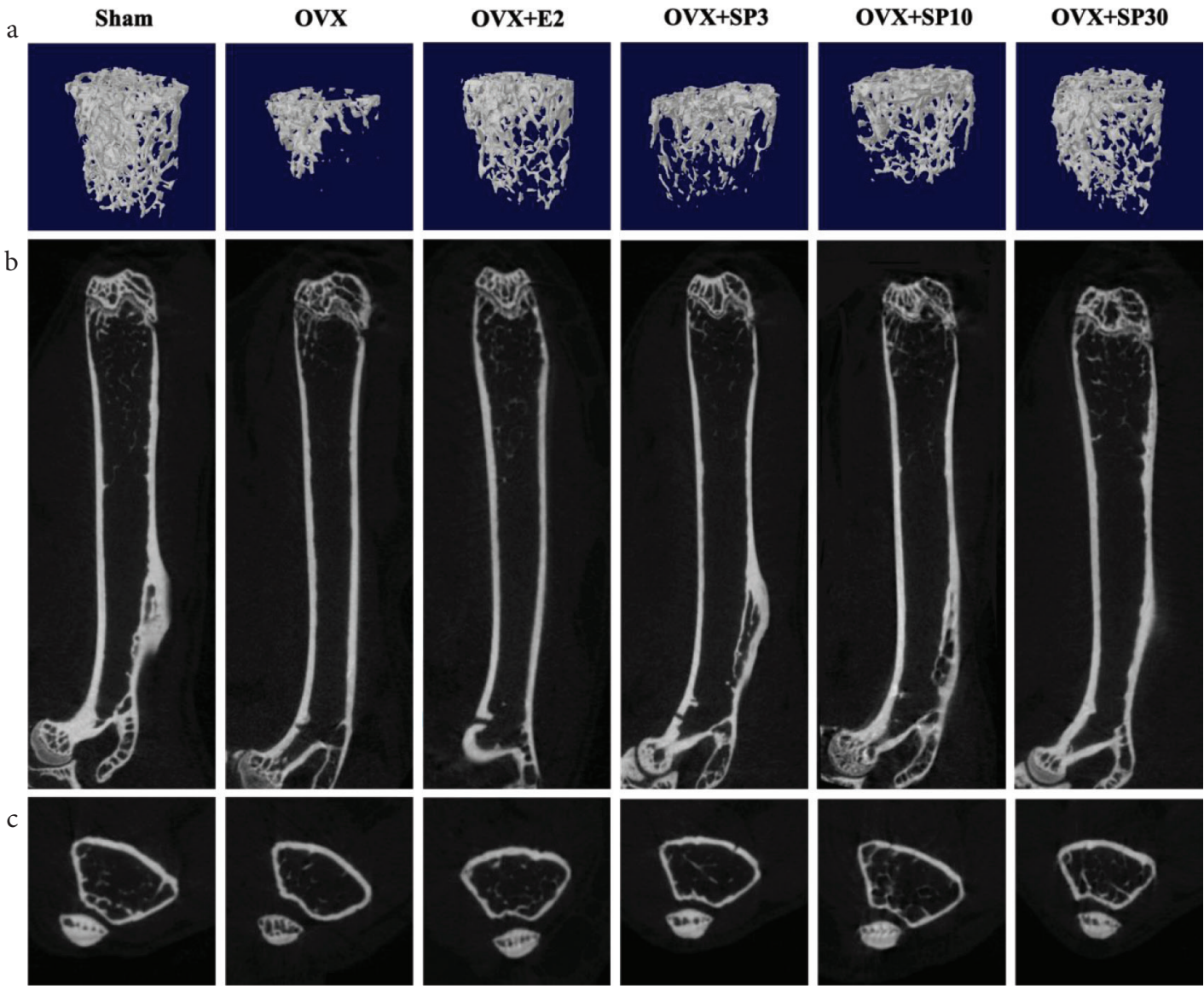

Figure 1 Osteopenia attenuated by oyster peptides below 3 KD and P-CG-01. (a) The 3D reconstruction of bone trabecula; (b) the trabecular profile $(X-Z$ axis); (c) the cross-sections of trabecula ( $X-Y$ axis). Sham, the group of removal of mouse fat tissue; OVX, the group of removal of mouse ovaries; OVX + E2, the group of OVX mice with subcutaneous injection of estrogen 2; OVX + SP3, OVX + SP10, OVX + SP30 was the groups of OVX mice with oral gavage of P-CG-01 in different concentrations, 3, 10, $30 \mathrm{mg} / \mathrm{kg} \cdot$ day, respectively. $\mathrm{KD}$, kilodalton.

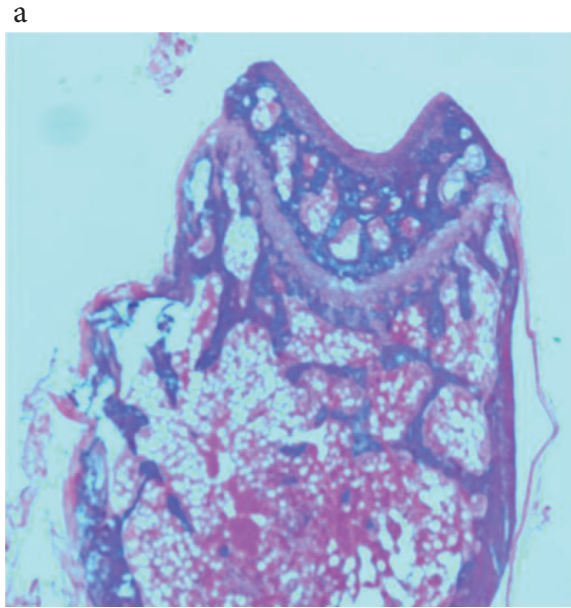

b

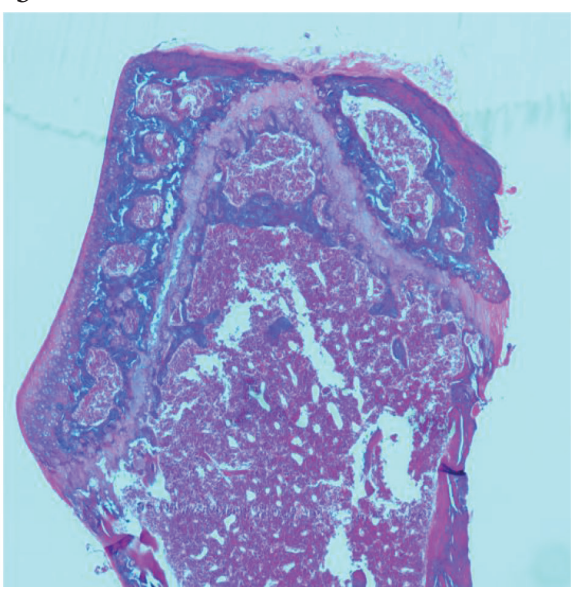

C

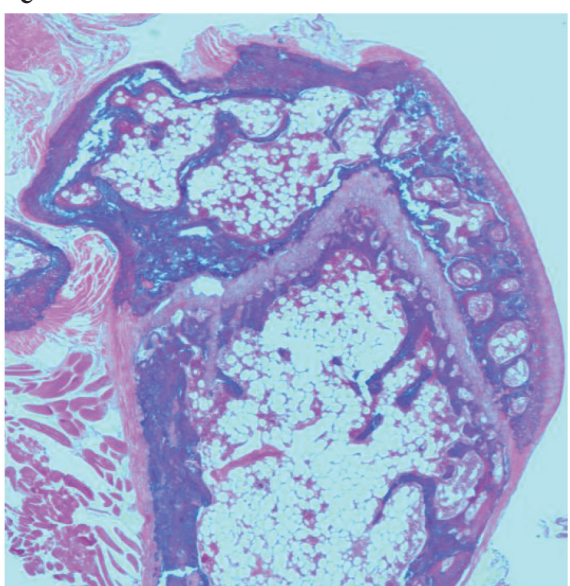

Figure 2 Slice staining of bone tissue. The slice was stained by Hematoxylin-Eosin. OVX, the group of removal of mouse ovaries; OVX + SP30 mean the group of OVX mice with oral gavage of P-CG-01 at $30 \mathrm{mg} / \mathrm{kg}$.day. The section was the area of trabecular. (a) Sham. (b) OVX. (c) OVX + SP30.

and the trend of trabecular separation was more concentrated. However, the trabecular thickness and trabecular pattern factors did not change (Figure 3). ALP and TRAP are the biomarkers that can be detected in blood, which are released from osteoblast and osteoclast. Only the ALP activity in serum of OVX + E group recovered to the level of Sham. However, ALP activity in OVX + SP30 was higher than that in OVX group, shown in Figure 4. The dephosphorylation of ALP causes it to produce phosphoric acid as an inorganic salt, hydroxyapatite, which releases synthetic bone matrix from osteoblasts [33]. TRAP activity of all group 

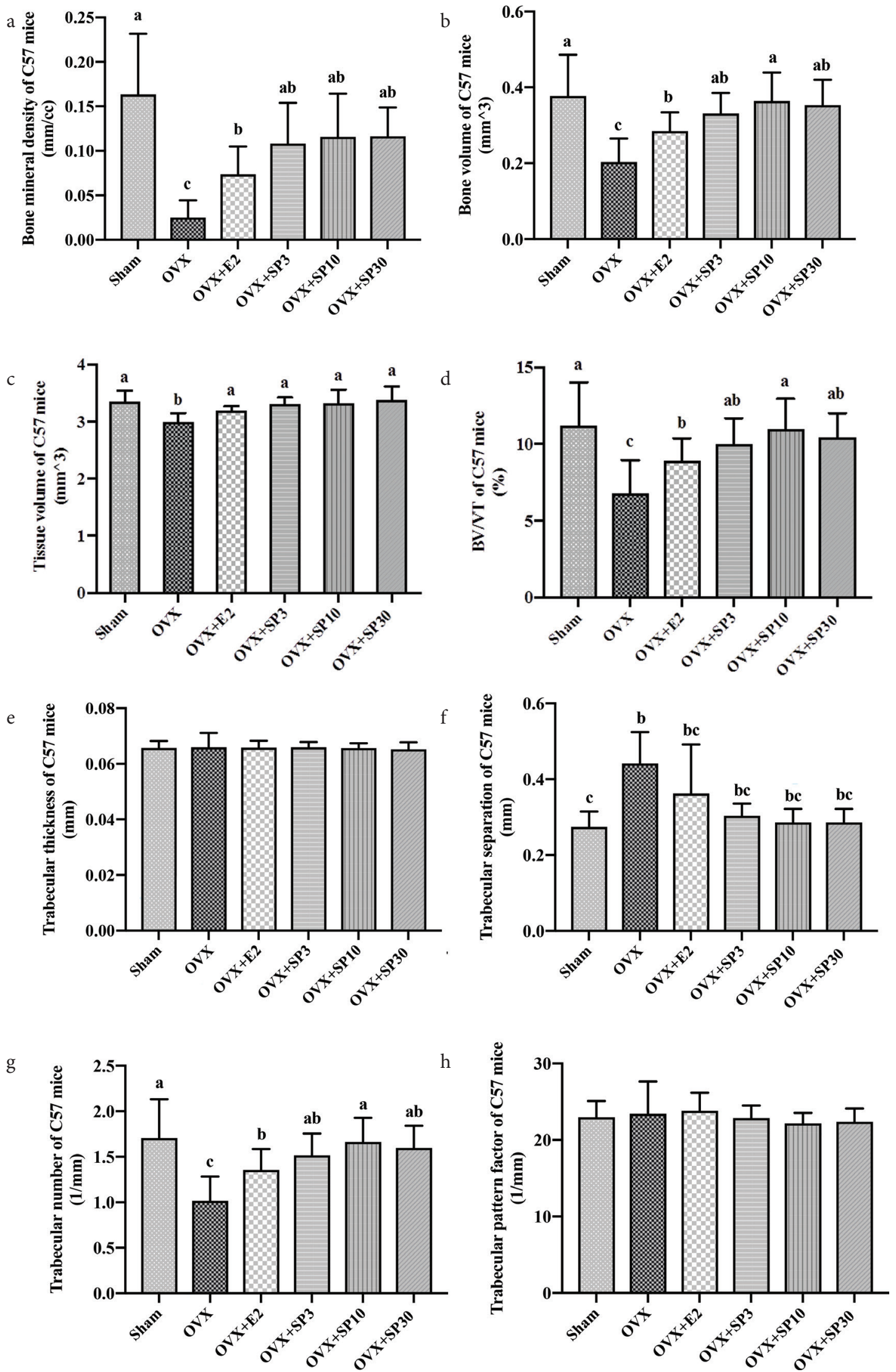

Figure 3 Bone microarchitecture of mice trabecular by micro-CT analysis. (a) BMD value of C57 mice, (b) bone volume, (c) tissue volume, (d) BV/TV, (e) trabecular thickness, (f) trabecular separation, (g) trabecular number, (h) trabecular pattern factor of C57 mice analyzed by micro-CT. 

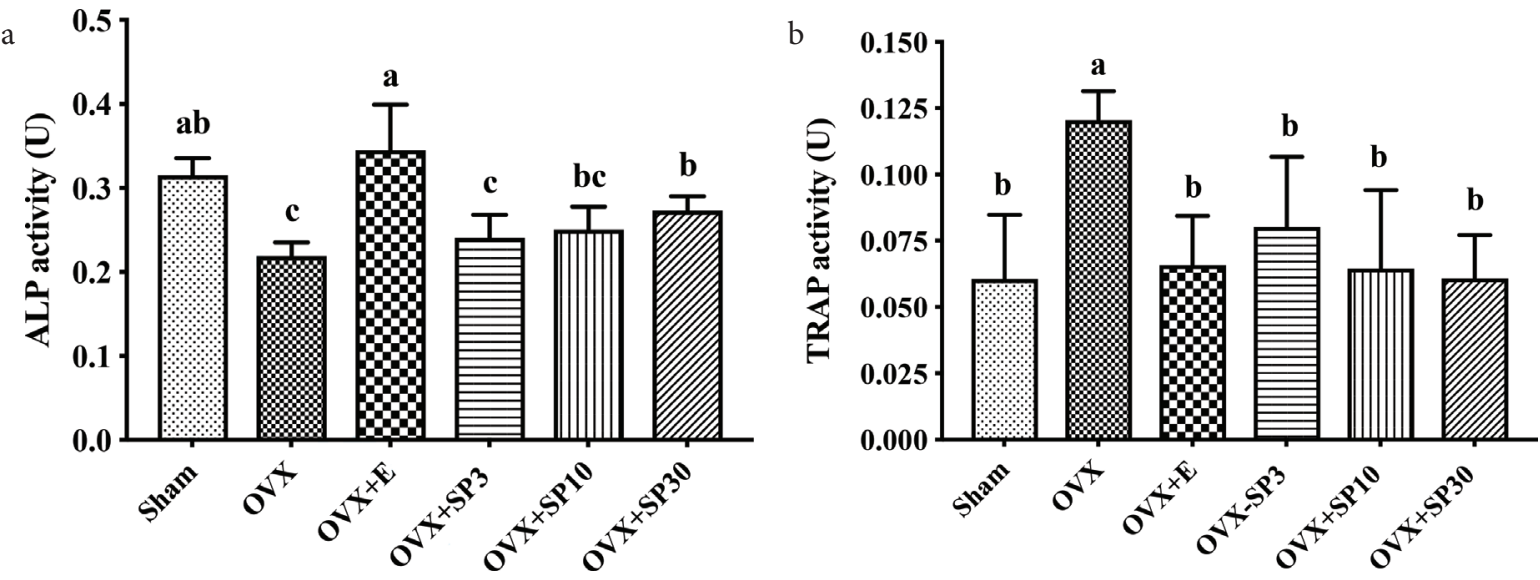

Figure 4 ALP and TRAP activities in C57 mouse serum. (a) ALP activity after treatment of $1 \mathrm{nM}, 10$ and $100 \mathrm{nM}$ P-CG-01; (b) TRAP activity after treatment of $1 \mathrm{nM}, 10$ and $100 \mathrm{nM}$ P-CG-01.

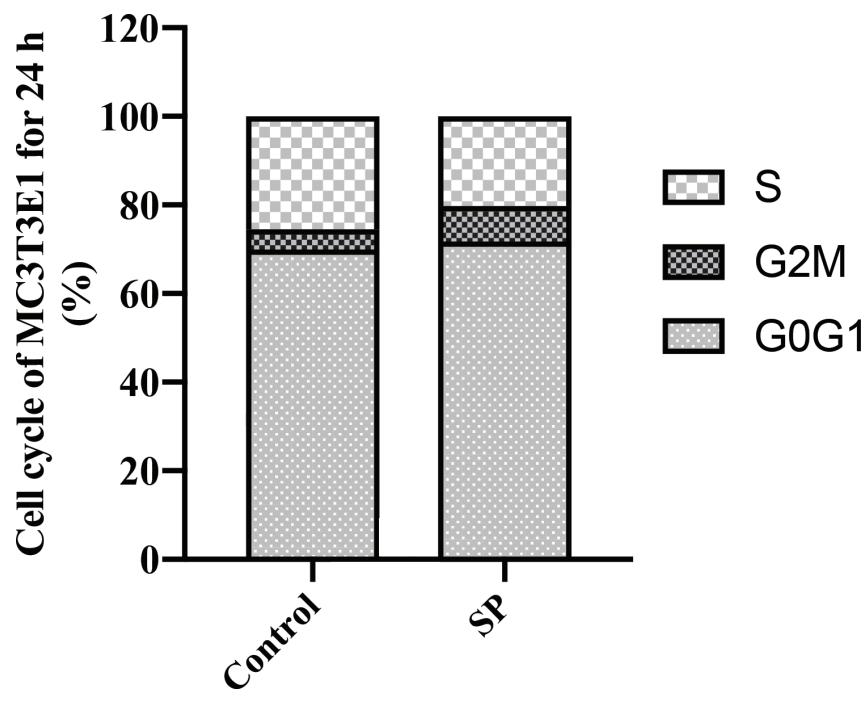

Figure 5 Cell cycle of MC3T3-E1 treated with P-CG-01. Analysis of cell cycle by FCM in S, G2M,G0G1 phase, treated with 100 nM P-CG-01.

treated with peptide recovered to the level of Sham as well as OVX + E. Therefore, results from bone trabecular microstructure and serum biomarker suggest that orally administration of peptides prevent the osteopenia in osteoporosis mice.

\subsection{Effects on Osteoblasts and Osteoclasts}

In our previous study, P-CG-01 can promote the proliferation of MC3T3-E1 cells [11]. We hypothesized that the cell cycle may be changed during the stimulation. The cell cycle of osteoblast was detected by flow cytometry (FCM). The nuclei were stained with PI. As we can see in Figure 5, after treatment with peptide for 3 days, the cell numbers of G2M phase increased, as well as the $\mathrm{S}$ phase. Not only the change of osteoblast, the effects of P-CG-01 on the osteoclasts were also discovered. RAW264.7 cell line was a macrophagocyte, that can be induced to differentiate into osteoclast by RANKL and Colony-stimulating Factor 1-Macrophage (M-SCF) [34]. RANKL is a factor secreted from osteoblast that interacts with RUNX2 on the surface of osteoclast, which acts as a promotor for osteoclast maturation and growth [35]. And M-SCF is a cytokine which is essential for survival and proliferation of mononuclear phagocytes. After combining those two factors for 7 days, when macrophagocytes were transformed into osteoclast, which is detected by the TRAP concentration assay. Afterward, osteoclast was treated with 1, 10,100 nM peptides and the cell viability by MTT assay decreased about $13 \%$ at $100 \mathrm{nM}$ suggesting that P-CG-01 can also slightly prevent the osteoclast multiplication. Figure 6 shows that the TRAP concentration increased $171 \%$ when RANKL and M-SCF were added, in contrast to control. Increase of TRAP was attenuated by 1,10 and $100 \mathrm{nM}$ peptide in a dosedependent manner.

\subsection{P-CG-01 Absorption in vitro and in vivo}

Peptide absorbed by Caco- 2 cells stimulates the penetration of itself from inside of intestine to the villus epithelial cell. In this study, MTT experiment was also used to investigate the effect of different concentrations of polypeptides on the activity of Caco-2 cells. No cell damage was found even at the highest concentration of $250 \mathrm{nM}$. Extremum of ALP activity was $3.49 \pm 0.43$ so that it was suitable for transwell assay of Caco-2 (Table S1, Supplementary Material) [36]. These ensured the biosafety of the peptides for the intestinal tract during absorption and utilization. As time increased, the body's peptide concentrations became higher and higher, reaching their peaks at $120 \mathrm{~min}$ (Figure 7). The peptide concentration in the top compartment also decreased with time. The results suggest that the peptide can be absorbed into the bloodstream through intestinal epithelial cells.

While, absorption of peptide in vivo of gastrointestinal tract was also investigated in C57 mice via oral administration. The peptide dose was the same as the treatment when it was used in the study of osteoporosis prevention in OVX mice. The results showed that when the peptide was administered through oral gavage, it can be absorbed through the barrier of intestinal villus into blood immediately. And the highest concentration was found at $10 \mathrm{~min}$ and the peptide at detectable dose maintained for $4 \mathrm{~h}$ in mouse serum (Figure 8). No matter the absorption assay in vitro or in vivo, P-CG-01 can be detected. Our results clearly suggest that although most of the peptide of protype was damaged, some levels of the peptide can break through the obstacles of gastro-intestine and absorbed into the circulation and it is crucial for osteogenesis. 
a

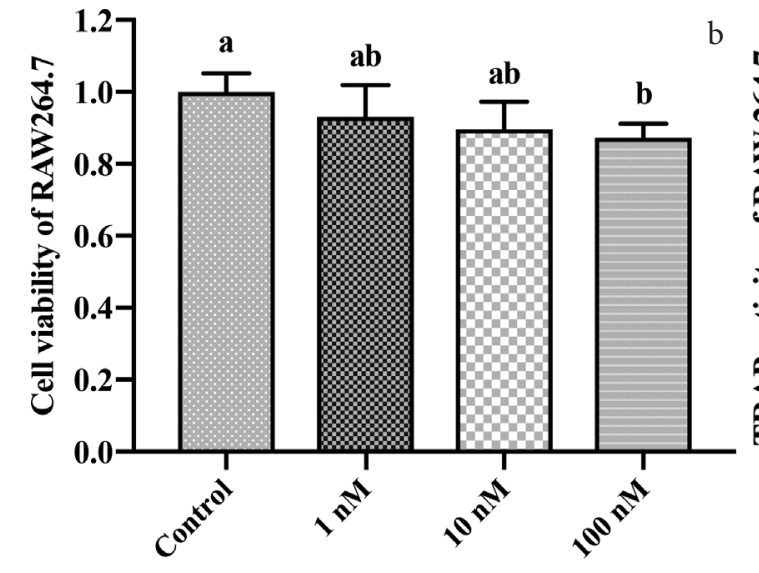

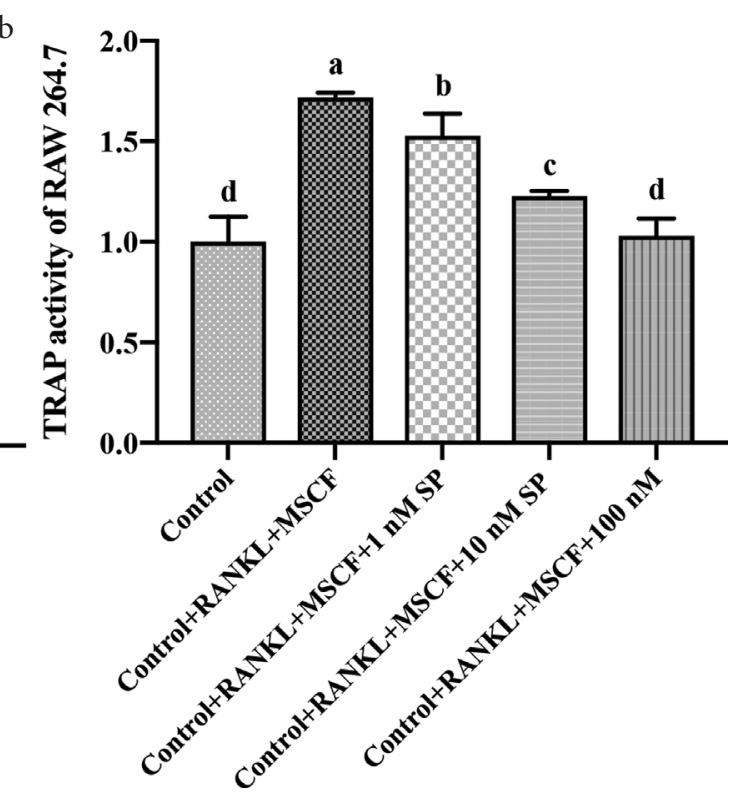

Figure 6 Inhibition of osteoclast differentiation by P-CG-01. (a) MTT assay of 1 nM, 10 and 100 nM treatment of P-CG-01, (b) TRAP activity of RAW264.7 inhibited by $1 \mathrm{nM}, 10$ and $100 \mathrm{nM}$ treatment of P-CG-01 after adding M-SCF and RANKL.
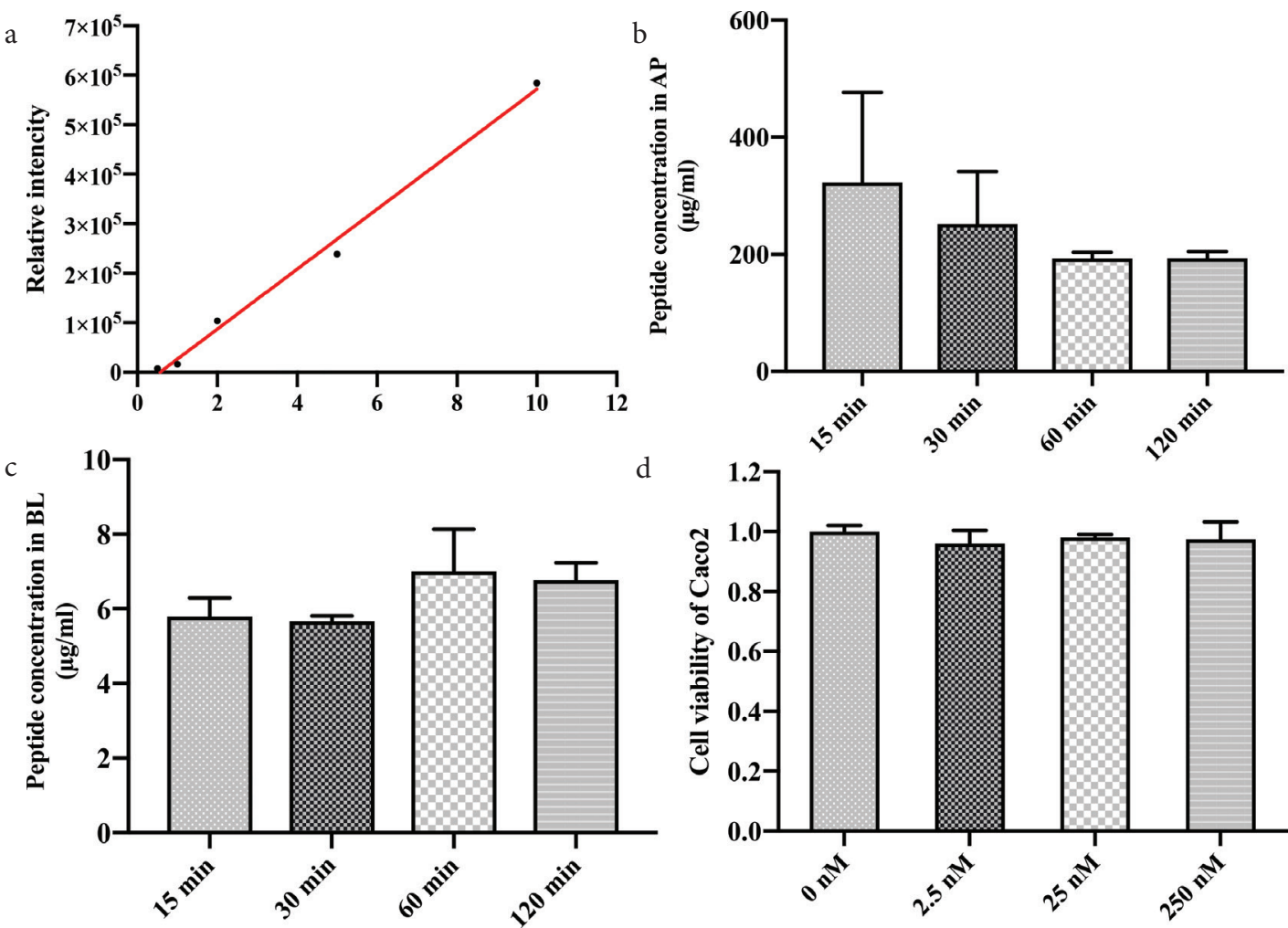

Figure 7 Peptide absorption of Caco-2 cells by transwell assay. (a) Standard curve of P-CG-01 detected by LC-MS; (b) P-CG-01 concentration in the AP compartment; (c) P-CG-01 concentration in the BL compartment; (d) MTT assay of Caco-2 cells treated by P-CG-01.

\subsection{Cellular Localization of P-CG-01 in Osteoblast}

In order to investigate the translocation of peptide YRGVVPK in the osteoblast. Generally, analysis of peptide localization in the cells can provide the clue. The peptide was synthesized with a fluorescent group of FITC. To investigate the cellular localization, labeled peptide was added into a confocal well. And the confocal well can be observed under the confocal microscope. Figure 9 shows that P-CG-01 was detected in cytoplasm with green florescence. 


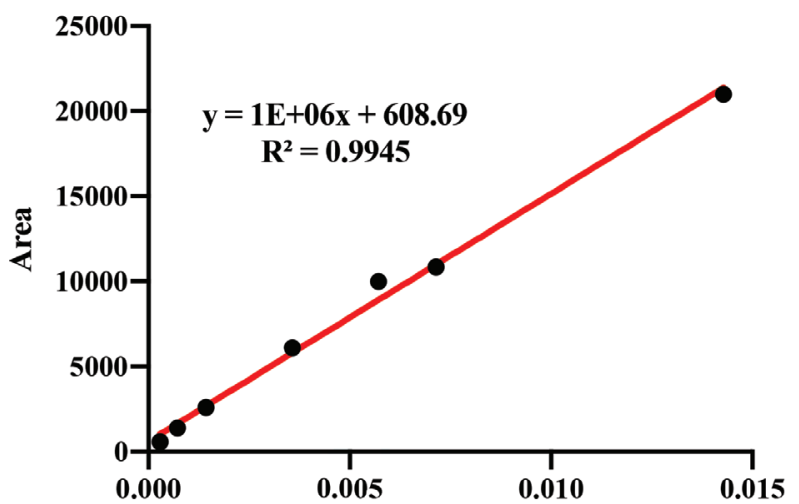

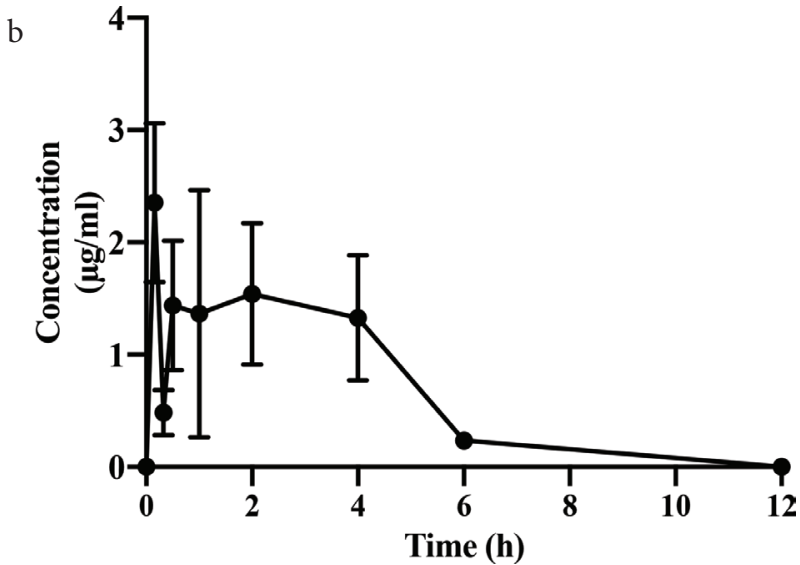

Figure 8 Peptide absorption into serum of mice. (a) Standard curve of P-CG-01 detected by LC-MS; (b) P-CG-01 concentration detected in mouse serum from $10 \mathrm{~min}$ to $12 \mathrm{~h}$ after intragastric administration.

FITC-P-CG-01
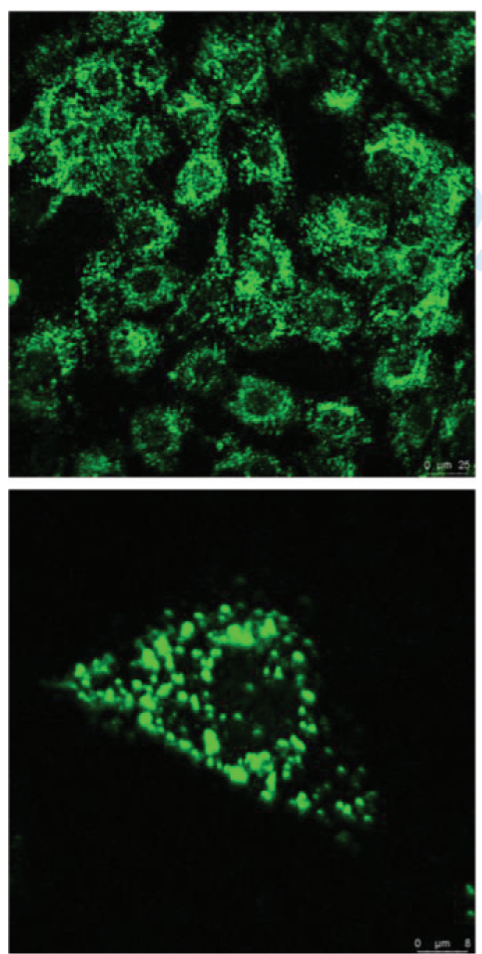

DAPI
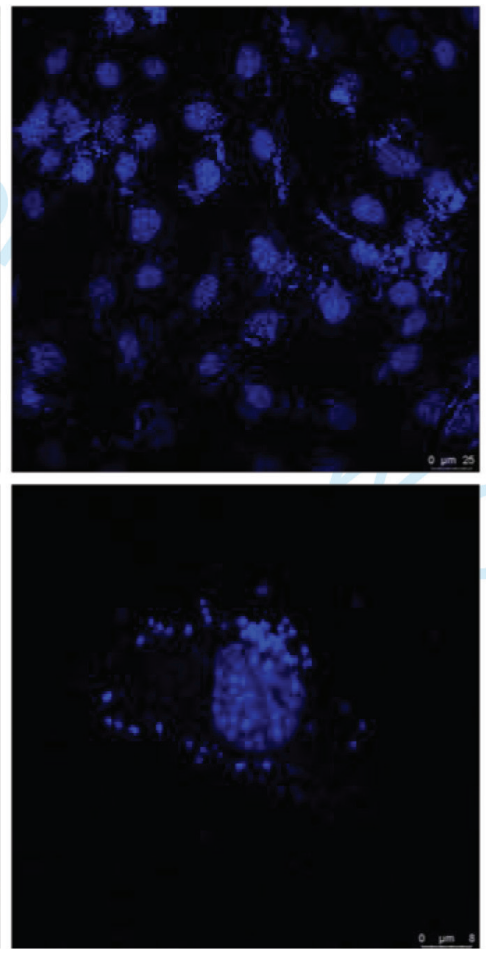

Merge
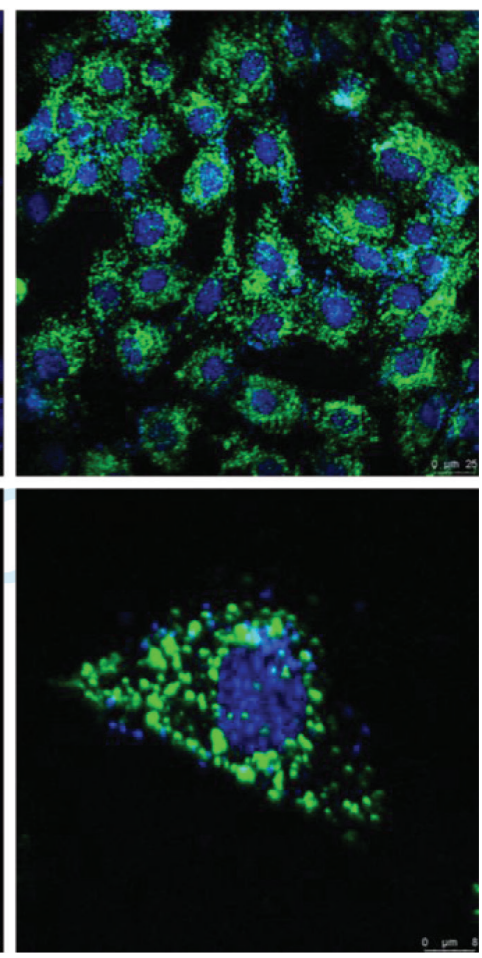

Figure 9 Peptide penetration into cytoplasm of MC3T3-E1 cells under confocal microscope. Green color in the cytoplasm area was P-CG-01-FITC, blue color was nuclei stained with DAPI, scare bar: $25 \mu \mathrm{m}$ and zoom in: $8 \mu \mathrm{m}$.

While the green florescence did not present in the nuclei, stained by DAPI. These results suggest that the peptide can penetrate through the membrane of osteoblast to play a bioactive function.

\subsection{Molecular Mechanism of Osteoblast Proliferation}

Gene expression of osteoblast affected by P-CG-01 was studied. Mitogen-activated protein kinase (MAPK) pathway is the principle route of cell proliferation, differentiation, apoptosis, and the study on MAPK pathway was widely reported [37,38]. In this study, osteoblast proliferation was increased, and cell circle was accelerated by the peptide. ERK1/2 and p38 are the subfamilies of MAPKs, which is highly involved in activating the signals and cellular responses through cell lifespan. ERK1/2 regulates cell proliferation and inhibits the apoptotic death against different stimuli from varies responses. And p38 in MAPK pathways has been suggested to participate in cell cycle control and cell multiplication [39]. The osteoblast signals requires the activation of ERK1/2 and p38 for its proliferation and differentiation [40-42]. Reports also showed that in osteoblast, ERK1/2 and p38 pathways are 

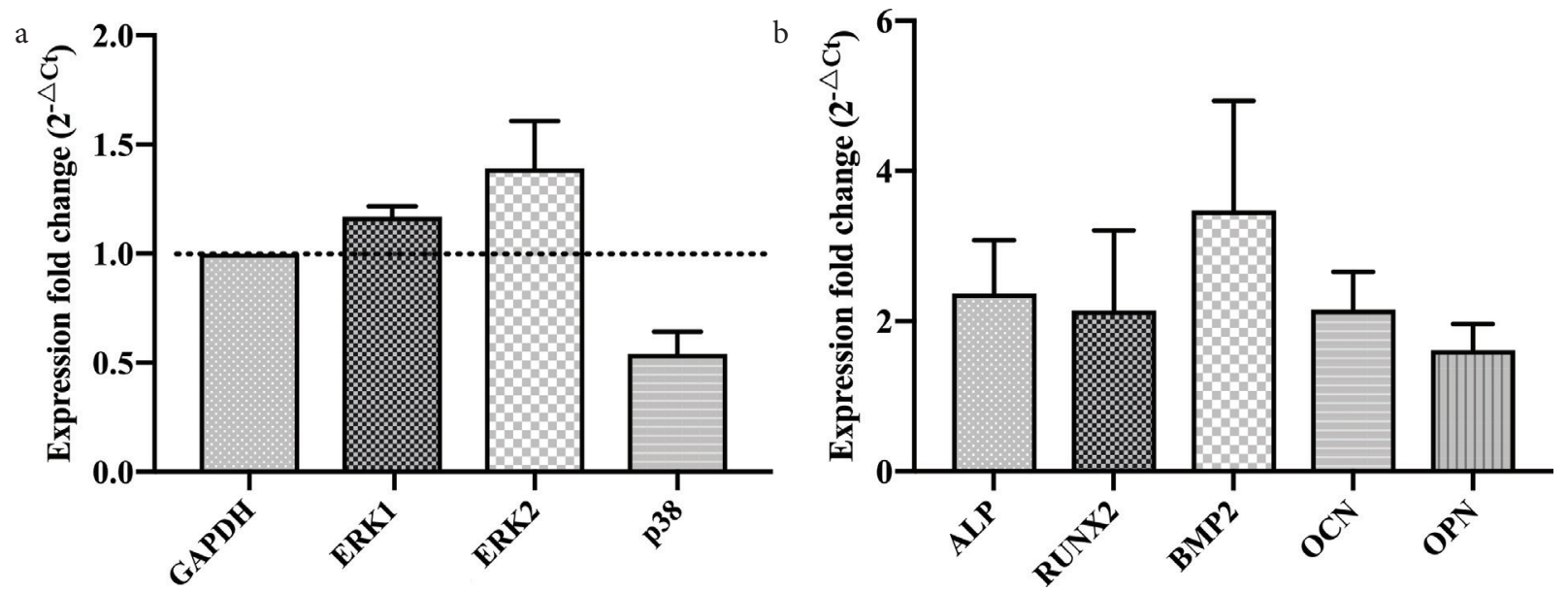

Figure 10 Gene expression level change of MC3T3-E1 cells treated by P-CG-01. (a) The MAPK pathway-related gene expression of MC3T3-E1 cells; (b) proliferation and secretion pathways-related gene expression of MC3T3-E1 cells.

modulated into a fast activation by action of ATP [40]. Figure 10 reveals that peptide treatment increased ERK 2 expression by 1.5 fold comparing to control. Interestingly, expression of p38 was decreased $50 \%$ by the peptide. This may suggest that p38 activation occurs in the early stage of osteoblast.

Runt-related transcription factor 2 (RUNX2) have been found to be essential for osteoblast differentiation, including the osteoblast differentiation from mesenchymal progenitors into maturation osteocytes $[43,44]$. RUNX2 can promote skeletal growth in both stages above. In OVX + SP30 group, RUNX2 level of change was about twofold. The gene of ALP was also increased twofold in OVX + SP30 group, and the regulation of mRNA was verified by the ALP concentration in the medium of osteoblast and in the serum of mice. The acceleration of cell reproduction and differentiation also leads to the improvement of osteogenesis. Bone mass or bone matrix contains a series of proteins in matrix, which is controlled by some promoting proteins, such as BMP-2, OCN, OPN. These proteins widely expressed in the extracellular matrix that are important for regulating the tissue integrity. BMP-2 was a key factor of the interest in the process of osteoblast proliferation and differentiation $[45,46]$. OCN is mainly synthesized by osteoblasts, odontoblast cells, and some by proliferating chondrocytes [47]. It plays an important role in regulating bone calcium metabolism and is a new biochemical marker for studying bone metabolism. The synthesis of OPN by early pre-osteoblasts is a $55 \mathrm{KD}$ hypophosphorylated protein, which may be related to the formation of bone matrix. Osteoblasts in early phase can synthesize a 44,000 hypophosphorylated OPN, which can regulate the growth of hydroxyapatite crystals. Therefore, OPN is considered as a marker of mature differentiation of osteoblasts $[48,49]$. The results of our study showed that peptide treatment led to increase in BMP-2 expression by about 3.8-fold. Levels of OCN and OPN were increased by about twofold (Figure 11). The results of the above osteoblasts demonstrate that this peptide increases the release of bone matrix and regulates bone matrix by accelerating the growth and differentiation rate of osteoblasts. Finally, the bone synthesis ability of osteoblasts is enhanced.
Control $1 \mathrm{nM} 10 \mathrm{nM} 100 \mathrm{nM}$

$\beta$-actin

BMP2

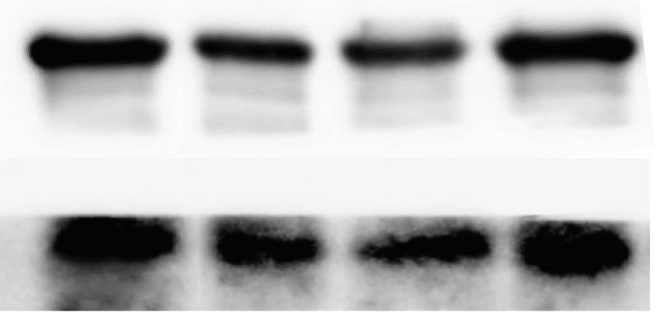

Runx2

JNK1

JNK2

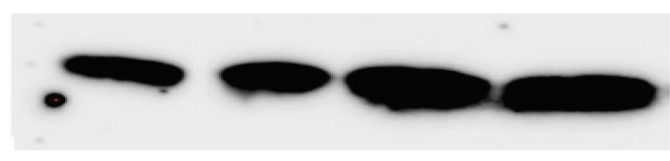

\section{ERK1}

ERK2

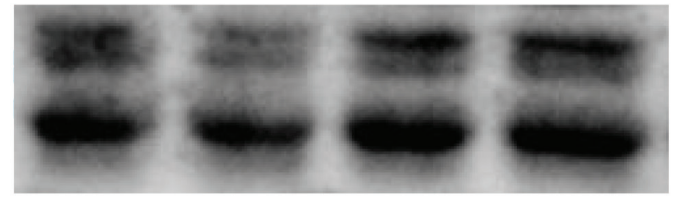

Figure 11 Western blot analysis of proliferation-related proteins from osteoblast treated by P-CG- 01 .

\section{CONCLUSION}

The main finding of our study in OVX + SP mice was that specific synthetic peptides significantly prevented BMD and the trabecular number from decreasing in the distal femur, in contrast to the OVX mice. OVX mice treated with peptide showed $7.7 \%$ higher BMD in the femoral trabecular, suggesting a preventive effect of the 2-month treatment with synthetic peptide. The anabolic effect 
of intake of synthetic peptide was also confirmed by a significant increase in the bone formation biomarkers, ALP and TRAP bone specific protein in mice. P-CG-01 can break through the obstacles of gastrointestinal tract barriers and enter into the osteoblast cytoplasm. Next, the mechanism of osteopenia of peptide was through the regulation of ERK1/2 MAPK pathway to enhance osteoblast viability. Meanwhile, it accompanied by gene expression that increased secretion of bone matrix proteins, such as BPM-2, OPN and OCN. In conclusion, P-CG-01 can inhibit the development of osteoporosis in ovariectomized mice.

\section{CONFLICTS OF INTEREST}

The authors declare they have no conflicts of interest.

\section{AUTHORS' CONTRIBUTION}

HC contributed in writing original draft preparation. PS, ZX and $\mathrm{ZW}$ contributed in writing review and editing. MD and FF contributed in supervision.

\section{ACKNOWLEDGMENT}

All the authors contributed to the works thank the financial support of National Natural Science Foundation of China (31771926) and the Project of Xingliao Talent Plan "Science and Technology Innovation Leader" (XLYC1802047).

\section{SUPPLEMENTARY MATERIALS}

Supplementary data related to this article can be found at https:// doi.org/10.2991/efood.k.200812.001.

\section{REFERENCES}

[1] Urano T, Inoue S. Genetics of osteoporosis. Biochem Biophys Res Commun 2014;452:287-93.

[2] Esbrit P, Herrera S, Portal-Núñez S, Nogués X, Díez-Pérez A. Parathyroid hormone-related protein analogs as osteoporosis therapies. Calcif Tissue Int 2016;98:359-69.

[3] Metcalf LM, Aspray TJ, McCloskey EV. The effects of parathyroid hormone peptides on the peripheral skeleton of postmenopausal women. A systematic review. Bone 2017;99:39-46.

[4] Troyan MB, Gilman VR, Gay CV. Mitochondrial membrane potential changes in osteoblasts treated with parathyroid hormone and estradiol. Exp Cell Res 1997;233:274-80.

[5] Ma JY, Wong KL, Xu ZY, Au KY, Lee NL, Su C, et al. N16, a nacreous protein, inhibits osteoclast differentiation and enhances osteogenesis. J Nat Prod 2016;79:204-12.

[6] John Martin T. Parathyroid hormone-related protein, its regulation of cartilage and bone development, and role in treating bone diseases. Physiol Rev 2016;96:831-71.

[7] Abdou AM, Watabe K, Yamane T, Isono T, Okamura Y, Kawahito S, et al. Antiosteoporotic effect of orally administered yolk-derived peptides on bone mass in women. Food Sci Nutr 2014;2:193-9.
[8] Cheung RCF, Ng TB, Wong JH. Marine peptides: bioactivities and applications. Mar Drugs 2015;13:4006-43.

[9] Xu M, Chen X, Gu Y, Peng T, Yang D, Chang RCC, et al. Baicalin can scavenge peroxynitrite and ameliorate endogenous peroxynitrite-mediated neurotoxicity in cerebral ischemiareperfusion injury. J Ethnopharmacol 2013;150:116-24.

[10] Xu Z, Chen H, Wang Z, Fan F, Shi P, Tu M, et al. Isolation and characterization of peptides from Mytilus edulis with osteogenic activity in mouse MC3T3-E1 preosteoblast cells. J Agric Food Chem 2019;67:1572-84.

[11] Chen H, Xu Z, Fan F, Shi P, Tu M, Wang Z, et al. Identification and mechanism evaluation of a novel osteogenesis promoting peptide from Tubulin Alpha-1C chain in Crassostrea gigas. Food Chem 2019;272:751-7.

[12] Ozawa H, Imamura K, Abe E, Takahashi N, Hiraide T, Shibasaki Y, et al. Effect of a continuously applied compressive pressure on mouse osteoblast-like cells (MC3T3-E1) in vitro. J Cell Physiol 1990;142:177-85.

[13] Elford PR, Felix R, Cecchini M, Trechsel U, Fleisch H. Murine osteoblastlike cells and the osteogenic cell MC3T3-E1 release a macrophage colony-stimulating activity in culture. Calcif Tissue Int 1987;41:151-6.

[14] Hotokezaka H, Sakai E, Kanaoka K, Saito K, Matsuo Ki, Kitaura H, et al. U0126 and PD98059, specific inhibitors of MEK, accelerate differentiation of RAW264.7 cells into osteoclast-like cells. J Biol Chem 2002;277:47366-72.

[15] Hirotani H, Tuohy NA, Woo JT, Stern PH, Clipstone NA. The calcineurin/nuclear factor of activated $\mathrm{T}$ cells signaling pathway regulates osteoclastogenesis in RAW264.7 cells. J Biol Chem 2004;279:13984-92.

[16] Kakita A, Suzuki A, Ono Y, Miura Y, Itoh M, Oiso Y. Possible involvement of p38 MAP kinase in prostaglandin E1-induced ALP activity in osteoblast-like cells. Prostaglandins Leukot Essent Fat Acids 2004;70:469-74.

[17] Hsu CW, Liu S, Hsu E, Hollinger JO. Inhibition of rhBMP-2induced ALP activity by intracellular delivery of SMURF1 in murine calvarial preosteoblast cells. J Biomed Mater Res A 2014; 102:4037-43.

[18] Hayman AR. Tartrate-resistant acid phosphatase (TRAP) and the osteoclast/immune cell dichotomy. Autoimmunity 2008;41:218-23.

[19] Ballanti P, Minisola S, Pacitti MT, Scarnecchia L, Rosso R, Mazzuoli GF, et al. Tartrate-resistant acid phosphatase (trap) activity as osteoclastic marker: comparison between cytochemical assessment and serum assay. Osteoporos Int 1996;6:168.

[20] Yu J, Huang NF, Wilson KD, Velotta JB, Huang M, Li Z, et al. nAChRs mediate human embryonic stem cell-derived endothelial cells: proliferation, apoptosis, and angiogenesis. PLoS One 2009;4:e7040.

[21] Liu YJ, Li W, Chang F, Liu JN, Lin JX, Chen DX. MicroRNA-505 is downregulated in human osteosarcoma and regulates cell proliferation, migration and invasion. Oncol Rep 2018;39: $491-500$

[22] Ni X, Zhai Z, Xin Z, Tan C, Chen Y, Deng J, et al. Antioxidant properties and transepithelial transportation of di-/tripeptides derived from simulated gastrointestinal digestion of pig blood cells hydrolysates. eFood 2020;1:254-69.

[23] Kindon H, Pothoulakis C, Thim L, Lynch-Devaney K, Podolsky DK. Trefoil peptide protection of intestinal epithelial barrier function: cooperative interaction with mucin glycoprotein. Gastroenterology 1995;109:516-23. 
[24] Cianciosi D, Forbes-Hernández TY, Afrin S, Gasparrini M, Quiles JL, Gil E, et al. The influence of in vitro gastrointestinal digestion on the anticancer activity of manuka honey. Antioxidants 2020;9:64.

[25] Liu M, Li P, Zeng X, Wu H, Su W, He J. Identification and pharmacokinetics of multiple potential bioactive constituents after oral administration of radix astragali on cyclophosphamideinduced immunosuppression in Balb/c mice. Int J Mol Sci 2015;16:5047-71.

[26] Hu G, Fan Y, Wang L, Yao RE, Huang X, Shen Y, et al. Copy number variations in 119 Chinese children with idiopathic short stature identified by the custom genome-wide microarray. Mol Cytogenet 2016;9:16.

[27] Smith CJ, Mark Osborn A. Advantages and limitations of quantitative PCR (Q-PCR)-based approaches in microbial ecology. FEMS Microbiol Ecol 2009;67:6-20.

[28] Zhang Q, Zhang Y, Zhang P, Chao Z, Xia F, Jiang C, et al. Hexokinase II inhibitor, 3-BrPA induced autophagy by stimulating ROS formation in human breast cancer cells. Genes Cancer 2014;5:100-12.

[29] Zhao F, Wang L, Liu K. In vitro anti-inflammatory effects of arctigenin, a lignan from Arctium lappa L., through inhibition on iNOS pathway. J Ethnopharmacol 2009;122:457-62.

[30] Meister ML, Mo H, Ji X, Shen CL. Tocotrienols in bone protection: evidence from preclinical studies. eFood 2020;1:217-25.

[31] Gonçalves C, Martins M, Costa MH, Costa PM. Development of a method for the detection of polystyrene microplastics in paraffin-embedded histological sections. Histochem Cell Biol 2018;149:187-91.

[32] Martelotto LG, Baslan T, Kendall J, Geyer FC, Burke KA, Spraggon L, et al. Whole-genome single-cell copy number profiling from formalin-fixed paraffin-embedded samples. Nat Med 2017;23:376-85.

[33] Fishman WH. Perspectives on alkaline phosphatase isoenzymes. Am J Med 1974;56:617-50.

[34] Shim KS, Ma CJ, Cho CW, Ma JY. Samul-tang suppresses RANKLinduced osteoclast differentiation in RAW264.7 cells. Biotechnol Bioprocess Eng 2011;16:603-10.

[35] Wada T, Nakashima T, Hiroshi N, Penninger JM. RANKL-RANK signaling in osteoclastogenesis and bone disease. Trends Mol Med 2006;12:17-25.

[36] Calhau C, Martel F, Hipólito-Reis C, Azevedo I. Effect of thiamine on $3 \mathrm{H}-\mathrm{MPP}+$ uptake by Caco-2 cells. Pharmacol Res 2003;48:579-84.

[37] Bhargava A, Pelech S, Woodard B, Kerwin J, Maherali N, Reproducibility Project: Cancer Biology; Reproducibility Project Cancer Biology. Registered report: RAF inhibitors prime wild-type
RAF to activate the MAPK pathway and enhance growth. elife 2016;5:e09976

[38] Rodríguez-Carballo E, Gámez B, Ventura F. p38 MAPK signaling in osteoblast differentiation. Front Cell Dev Biol 2016;4:40.

[39] Yang GH, Jarvis BB, Chung YJ, Pestka JJ. Apoptosis induction by the satratoxins and other trichothecene mycotoxins: relationship to ERK, p38 MAPK, and SAPK/JNK activation. Toxicol Appl Pharmacol 2000;164:149-60.

[40] Katz S, Boland R, Santillán G. Modulation of ERK 1/2 and p38 MAPK signaling pathways by ATP in osteoblasts: involvement of mechanical stress-activated calcium influx, PKC and Src activation. Int J Biochem Cell Biol 2006;38:2082-91.

[41] Hu Y, Chan E, Wang SX, Li B. Activation of p38 mitogenactivated protein kinase is required for osteoblast differentiation. Endocrinology 2003;144:2068-74.

[42] Raucci A, Bellosta P, Grassi R, Basilico C, Mansukhani A. Osteoblast proliferation or differentiation is regulated by relative strengths of opposing signaling pathways. J Cell Physiol 2008;215:442-51.

[43] Franceschi RT, Xiao G. Regulation of the osteoblast-specific transcription factor, Runx2: responsiveness to multiple signal transduction pathways. J Cell Biochem 2003;88:446-54.

[44] Komori T. Runx2, an inducer of osteoblast and chondrocyte differentiation. Histochem Cell Biol 2018;149:313-23.

[45] Rawadi G, Vayssière B, Dunn F, Baron R, Roman-Roman S. BMP-2 controls alkaline phosphatase expression and osteoblast mineralization by a Wnt autocrine loop. J Bone Miner Res 2003;18:1842-53.

[46] Ma XY, Feng YF, Wang TS, Lei W, Li X, Zhou DP, et al. Involvement of FAK-mediated BMP-2/Smad pathway in mediating osteoblast adhesion and differentiation on nano-HA/chitosan composite coated titanium implant under diabetic conditions. Biomater Sci 2018;6:225-38.

[47] Hoffmann HM, Beumer TL, Rahman S, McCabe LR, Banerjee C, Aslam F, et al. Bone tissue-specific transcription of the osteocalcin gene: role of an activator osteoblast-specific complex and suppressor Hox proteins that bind the OC box. J Cell Biochem $1996 ; 61: 310-24$.

[48] Noda M, Rodan GA. Transcriptional regulation of osteopontin production in rat osteoblast-like cells by parathyroid hormone. J Cell Biol 1989;108:713-18.

[49] Kusuyama J, Bandow K, Ohnishi T, Hisadome M, Shima K, Semba I, et al. Osteopontin inhibits osteoblast responsiveness through the down-regulation of focal adhesion kinase mediated by the induction of low-molecular weight protein tyrosine phosphatase. Mol Biol Cell 2017;28:1326-36. 